\title{
EFFECTS OF DIETARY FIBER AND BENZOIC ACID ON GROWTH PERFORMANCE, NUTRIENT DIGESTIBILITY, REDUCTION OF HARMFUL GASES, AND LIPID PROFILES IN GROWING PIGS
}

\author{
Subramaniam Mohana Devi ${ }^{1}$, Jin Young Cheong ${ }^{1,2}$, In Ho Kim ${ }^{1 *}$ \\ ${ }^{1}$ Department of Animal Resource and Science, Dankook University, No. 29 Anseodong, Cheonan, \\ Chungnam 330-714, South Korea \\ ${ }^{2}$ Daehan Feed Co., Ltd, 13, Bukseongpo-gil, Jung-gu, Incheon 400-201, South Korea \\ •Corresponding author: inhokim@dankook.ac.kr
}

\begin{abstract}
We assessed the possibly synergistic effects of dietary fiber (DF) and benzoic acid (BA) in growingfinishing pigs. In total, 96 growing pigs ([Landrace $\times$ Yorkshire] $\times$ Duroc) with an average initial body weight $(\mathrm{BW})$ of $22.82( \pm 0.24) \mathrm{kg}$ were selected and provided the dietary supplements based on their BW in a $2 \times 2$ factorial experiment, with the respective factors being fiber (low vs. high; $140 \mathrm{~g} / \mathrm{kg}, 160 \mathrm{~g} / \mathrm{kg}$ NSP, respectively) and BA $(0,5 \mathrm{~g} / \mathrm{kg}$ benzoic acid) in six replicate pens consisting of four pigs per pen. Sugar beet pulp was used as a DF source, at $50 \mathrm{~g} / \mathrm{kg}$ of the diet. All diets were formulated to contain $14.44 \mathrm{ME} \mathrm{MJ/kg}$ and $190 \mathrm{~g} / \mathrm{kg} \mathrm{CP}$. This experiment was conducted to evaluate the growth performance, nutrient digestibility, and reduction of harmful gases and serum metabolites. There was no significant difference in feed intake and weight gains during treatments. Fiber levels and benzoic acid addition did not affect the dry matter, nitrogen and gross energy digestibility. Also, no interaction was found between fiber level and benzoic acid treatment. There was no difference in $\mathrm{NH}_{3}$, but $\mathrm{RSH}$ and $\mathrm{H}_{2} \mathrm{~S}$ gases emissions show significant reduction with fiber and benzoic acid treatment. Serum metabolites, including lipoprotein and cholesterol, were also apparently unaffected by these treatments. Thus, the addition of $50 \mathrm{~g}$ sugar beet pulp per $\mathrm{kg}$ of growing feed as a DF source and the addition of BA had no significant impact on the growth performance of pigs during the growth period.
\end{abstract}

Key words: fiber, benzoic acid, growing pigs, lipid profile, gas emission

Dietary fiber (DF) is a beneficial nutrient for reducing harmful gas emissions (Mosenthin et al., 1992; Zervas and Zijlstra, 2002; Nahm, 2003), decreasing the incidence of diarrhea and constipation (Mateos et al., 2006; Pierce et al., 2007; Wellock et al., 2008), and improving social behavior (Meunier-Salaun et al., 2001; Serena et al., 2009) in pigs. Dietary fiber has also been associated with possible protective benefits against several human illnesses, such as coronary heart disease, diabetes, 
and constipation (Chandalia et al., 2000; Schulze et al., 2004; McMillan-Price et al., 2006). However, negative effects of DF on growth performance of pigs, such as reducing feed intake and growth retardation due to early satiety and nutrient encapsulation have also been reported (Zervas and Zijlstar, 2002).

Several feed additives, including acidifiers (Wang et al., 2009), enzymes (Cho et al., 2013), probiotics (Zhang and Kim, 2013), prebiotics, (Cho and Kim, 2014), medium chain triglycerides (Hong et al., 2012) and plant extracts (Yan and Kim, 2012) have been introduced in the pig and poultry industry as nutritional tools to improve the growth performance of pig and poultry. Benzoic acid (BA) is one acidifier, which has also been reported to have positive effects in reducing ammonia emission and increasing weight gain in pigs (Cheong, 2013; Buhler et al., 2006; Sauer et al., 2009). It exerts strong antimicrobial effects in the gastrointestinal tract of piglets (Kluge et al., 2006), reduces the pH of the urine (Kluge et al., 2010), and improves growth performance and reduces the severity of diarrhea in weaning pigs (Papatsiros et al., 2011). Additionally, BA has the possibility of reducing LDL cholesterol due to its chemical similarity to niacin (Jin et al., 1999).

The purpose of this study was to assess whether DF and BA have any synergistic effect on growth performance, nutrient digestibility, harmful gas emissions, and serum metabolites in the growing pigs.

\section{Material and methods}

\section{Experimental design, animals, and diets}

The Animal Care and Use Committee of Dankook University, South Korea approved the experimental protocols used in this study. In total, 96 grower pigs [(Landrace $\times$ Yorkshire $) \times$ Duroc] with an average initial BW of $22.82( \pm 0.24) \mathrm{kg}$ were selected and allotted to dietary treatments based on their BW in a $2 \times 2$ factorial experiment. The factors were DF (low vs. high; 140 and $160 \mathrm{~g} / \mathrm{kg}$ NSP, respectively) and BA (0 and $5 \mathrm{~g} / \mathrm{kg} \mathrm{BA})$ with six replicate pens consisting of four pigs per pen. Sugar beet pulp was included at $50 \mathrm{~g} / \mathrm{kg}$ as the source of DF.

Experimental diets were conventional Korean diets mainly based on corn, wheat, and soybean meal. This feed was produced at a commercial feed mill and provided as mash. All diets were formulated to contain 14.44 MJ ME/kg and $190 \mathrm{~g} / \mathrm{kg} \mathrm{CP}$ (Table 1). Pigs were housed in an environmentally controlled facility with slatted plastic flooring and a mechanical ventilation system. Each pen was equipped with a single face self-feeder and a nipple drinker to allow the pigs ad libitum access to feed and water throughout the experimental period.

\section{Sampling and recorded parameters}

Parameters such as growth performance, nutrient digestibility, noxious gas emission, and lipid profiles were analyzed in this study. Health parameters, such as morbidity, mortality, and diarrhea score were not analyzed because we maintained an allin all-out system for the maintenance of the pigs, in which all the pigs from weaning to finishing were maintained hygienically. 
Table 1. Composition of the experimental diets for growing pigs, as-fed basis

\begin{tabular}{|c|c|c|c|c|}
\hline \multirow{2}{*}{$\frac{\text { Dietary Fiber level (DF) }}{1}$} & \multicolumn{2}{|c|}{ Low } & \multicolumn{2}{|c|}{ High } \\
\hline & 0 & 5 & 0 & 5 \\
\hline \multicolumn{5}{|l|}{ Ingredient (g/kg) } \\
\hline corn & 430.3 & 425.3 & 373.0 & 368.0 \\
\hline wheat & 200.0 & 200.0 & 200.0 & 200.0 \\
\hline beet pulp & & & 50.0 & 50.0 \\
\hline soybean meal & 276.0 & 276.0 & 279.0 & 279.0 \\
\hline animal fat & 26.7 & 26.7 & 32.4 & 32.4 \\
\hline soy oil & 10.0 & 10.0 & 10.0 & 10.0 \\
\hline molasses & 20.0 & 20.0 & 20.0 & 20.0 \\
\hline limestone & 10.0 & 10.0 & 9.0 & 9.0 \\
\hline Di-calcium phosphate & 11.0 & 11.0 & 11.0 & 11.0 \\
\hline salt & 3.0 & 3.0 & 3.0 & 3.0 \\
\hline Benzoic acid & & 5.0 & & 5.0 \\
\hline DL-Methionine & 0.7 & 0.7 & 0.8 & 0.8 \\
\hline L-Lysine $\mathrm{HCl}(25 \%)$ & 8.6 & 8.6 & 8.1 & 8.1 \\
\hline L-Threonine $(10 \%)$ & 0.5 & 0.5 & 0.5 & 0.5 \\
\hline vitamin premix ${ }^{3}$ & 1.7 & 1.7 & 1.7 & 1.7 \\
\hline mineral premix ${ }^{4}$ & 1.0 & 1.0 & 1.0 & 1.0 \\
\hline Phytase & 0.5 & 0.5 & 0.5 & 0.5 \\
\hline \multicolumn{5}{|l|}{ Calculated composition } \\
\hline ME (MJ/kg) & 14.44 & 14.44 & 14.44 & 14.44 \\
\hline $\mathrm{CP}(\mathrm{g} / \mathrm{kg})$ & 188.4 & 188.0 & 190.1 & 189.8 \\
\hline SID Lysine $(\mathrm{g} / \mathrm{kg})$ & 10.8 & 10.8 & 10.8 & 10.8 \\
\hline Fiber $(\mathrm{g} / \mathrm{kg})$ & 28.0 & 28.0 & 36.6 & 36.5 \\
\hline $\mathrm{NSP}(\mathrm{g} / \mathrm{kg})^{5}$ & 140.2 & 144.0 & 160.5 & 164.4 \\
\hline $\mathrm{Ca}(\mathrm{g} / \mathrm{kg})$ & 7.6 & 7.6 & 7.6 & 7.6 \\
\hline $\mathrm{P}(\mathrm{g} / \mathrm{kg})$ & 5.4 & 5.3 & 5.3 & 5.3 \\
\hline
\end{tabular}

${ }^{1}$ Dietary Fiber.

${ }^{2}$ Benzoic acid: VevoVitall, DSM Nutrition Products, Basel, Switzerland.

${ }^{3}$ Vitamin premix provided/kg complete diet: IU: vit. $\mathrm{A}-10000$, vit. $\mathrm{D}_{3}-2000$, vit. $\mathrm{E}-80$; mg: vit. $\mathrm{K}-2$, vit. $\mathrm{B}_{2}-4$, vit. $\mathrm{B}_{6}-3$, pantothenic acid -15 , niacin -40 , biotin $-0.04 ; \mu \mathrm{g}$ : vit. $\mathrm{B}_{12}-40$.

${ }^{4}$ Mineral premix provided/kg complete diet: $\mathrm{mg}: \mathrm{Cu}-50, \mathrm{Fe}-150, \mathrm{Zn}-100, \mathrm{Mn}-40, \mathrm{I}-0.5, \mathrm{Co}-0.5$, $\mathrm{Se}-0.3$

${ }^{5} \mathrm{NSP}-$ Non-starch polysaccharide, determined as Organic matter $-($ crude protein + crude lipid + starch + sugar).

\section{Growth performance and nutrient digestibility}

The live BW of each individual pig was measured at the beginning and end (42 days) of the experimental period. Feed consumption was also recorded and gain/feed ratio was calculated on a pen basis.

At the beginning of the fifth week (28 d), chromium oxide $\left(\mathrm{Cr}_{2} \mathrm{O}_{3}, 2 \mathrm{~g} / \mathrm{kg}\right.$ ) was added to the diet as an indigestible marker to measure digestibility. Fresh fecal grab samples were obtained from at least two pigs in each pen at the end of the fifth week to determine the apparent digestibility of dry matter (DM), nitrogen (N), and gross energy (GE). All fecal and feed samples were stored at $-20^{\circ} \mathrm{C}$ until analyzed. Fecal samples were freeze-dried and ground to pass through a 1-mm screen. The feed and fecal samples were analyzed for DM, N, and E according to AOAC (2000). Chromium was analyzed by UV absorption spectrophotometry (Shimadzu UV-1201, Shimadzu, Kyoto, Japan) following the method described by Williams et al. (1962). 


\section{Noxious gas emission from slurry}

On day 35, the urine and feces of two pigs per pen were collected separately, four times a day, to evaluate emissions of certain harmful gases: ammonia $\left(\mathrm{NH}_{3}\right)$, hydrogen sulfide $\left(\mathrm{H}_{2} \mathrm{~S}\right)$, and mercaptans $(\mathrm{RSH})$. The urine was collected in a bucket via a funnel positioned below the cage. The feces were collected in a plastic sample bag and sealed. The feces collected from each animal during the final $5 \mathrm{~d}$ of the experimental period were used for detecting gas emissions. The collected urine and feces were stored immediately at $-20^{\circ} \mathrm{C}$ and $4{ }^{\circ} \mathrm{C}$, respectively. After the collection period, the fresh feces $(300 \mathrm{~g})$ were mixed with $300 \mathrm{~mL}$ of fresh urine $(1: 1, \mathrm{w} / \mathrm{v})$ for each pig. The stock slurries were stored in 2.6-L plastic boxes in duplicate. Each box had a small hole in the middle of one sidewall, which was sealed with adhesive plaster. The samples were allowed to ferment for a period of $24 \mathrm{~h}$ at room temperature $\left(25^{\circ} \mathrm{C}\right)$. After the fermentation period, a Gastec (model GV-100) gas-sampling pump was used for gas detection (Gastec Corp., Gastec detector tube No. $3 \mathrm{M}$ and $3 \mathrm{La}$ for $\mathrm{NH}_{3}$, No. $4 \mathrm{LL}$ and $4 \mathrm{LK}$ for $\mathrm{H}_{2} \mathrm{~S}$, and No. 70 and $70 \mathrm{~L}$ for RSH). Prior to measurement, the manure slurries were shaken manually for $\sim 30 \mathrm{~s}$ to disrupt any crust formation on the surface of the slurry sample and to homogenize them. The adhesive plaster was punctured and $100 \mathrm{~mL}$ of headspace air was sampled $\sim 2.0 \mathrm{~cm}$ above the feces surface. After air sampling, each box was again covered with adhesive plaster. Headspace measurements were repeated at 1, 3, 5, and $7 \mathrm{~d}$ after feces collection. The gas was averaged from the measurements of two boxes from the same pen.

\section{Blood lipid profile}

Two pigs were selected randomly from each pen and the blood samples were collected by jugular venipuncture at the beginning $(0 \mathrm{~d})$ and at the end $(42 \mathrm{~d})$ of the experiment. Blood samples were collected in $\mathrm{K}_{3}$ EDTA coated tubes (Becton Dickinson Vacutainer System, Franklin Lakes, NJ, USA) and then centrifuged $(2000 \times \mathrm{g}$, $20 \mathrm{~min}, 4^{\circ} \mathrm{C}$ ) within $1 \mathrm{~h}$ after the collection of the sample to separate the serum. The concentrations of total, low density lipoprotein (LDL)- and high density lipoprotein (HDL)-cholesterol, non-esterified fatty acids (NEFA), and triglycerides (TG) in the serum samples were analyzed with an automatic biochemical analyzer (RA-1000, Bayer Corp., Tarrytown, NY) using colorimetric methods.

\section{Statistical analyses}

The data sets obtained were analyzed as a completely randomized $2 \times 2$ factorial design, using the GLM procedure of the SAS software (SAS Inst. Inc., Cary, NC, 2009). The pen was considered the experimental unit for growth performance and each pig was considered the experimental unit for gas emission and serum metabolites. The final model included the main effects of DF level and BA as well as the interaction between DF and BA. Data are reported as means \pm standard error (SE). Differences were considered statistically significant when $\mathrm{P}<0.05$. 


\section{Results}

\section{Growth performance and nutrient digestibility}

The growth performance and apparent nutrient digestibility are shown in Tables 2 and 3 . In the current study, final BW, average daily gain (ADG) and feed efficiency (gain:feed) were not influenced by treatments or their interaction. There was no significant difference in feed intake in low fiber (LF) and high fiber (HF) groups (Table 2). Also it was found that experimental treatment did not significantly affect the dry matter, nitrogen and gross energy digestibility (Table 3).

Table 2. Effects of dietary fiber (DF) and benzoic acid (BA) on growth performance in growing pigs

\begin{tabular}{|c|c|c|c|c|c|c|c|c|}
\hline Dietary Fiber level (DF) ${ }^{1}$ & \multicolumn{2}{|c|}{ Low } & \multicolumn{2}{|c|}{ High } & \multirow{2}{*}{$\mathrm{SE}^{3}$} & \multicolumn{3}{|c|}{ P-value } \\
\hline Benzoic Acid (BA) $)^{2} \%$ & 0 & 5 & 0 & 5 & & DF & BA & $\mathrm{DF} \times \mathrm{BA}$ \\
\hline Initial BW (kg) & 22.82 & 22.83 & 22.83 & 22.81 & 0.111 & 0.9134 & 0.8562 & 0.7720 \\
\hline Final BW $(\mathrm{kg})$ & 49.92 & 50.83 & 50.41 & 50.34 & 1.498 & 0.4023 & 0.8781 & 0.5275 \\
\hline $\mathrm{ADG}(\mathrm{kg})$ & 0.645 & 0.667 & 0.657 & 0.660 & 0.036 & 0.4055 & 0.8720 & 0.5612 \\
\hline ADFI (kg) & 1.463 & 1.441 & 1.443 & 1.428 & 0.168 & 0.987 & 0.891 & 0.5197 \\
\hline Gain/Feed & 0.441 & 0.463 & 0.455 & 0.462 & 0.024 & 0.1624 & 0.5009 & 0.4730 \\
\hline
\end{tabular}

${ }^{1}$ Dietary Fiber.

${ }^{2}$ Benzoic acid: VevoVitall, DSM Nutrition Products, Basel, Switzerland.

${ }^{3}$ Standard error.

Table 3. Effects of dietary fiber (DF) and benzoic acid (BA) on the apparent total tract digestibility (\%) in growing pigs

\begin{tabular}{|c|c|c|c|c|c|c|c|c|}
\hline Dietary Fiber level (DF) ${ }^{1}$ & \multicolumn{2}{|c|}{ Low } & \multicolumn{2}{|c|}{ High } & \multirow{2}{*}{$\mathrm{SE}^{3}$} & \multicolumn{3}{|c|}{ P-value } \\
\hline Benzoic Acid (BA) $\%$ & 0 & 5 & 0 & 5 & & DF & BA & $\mathrm{DF} \times \mathrm{BA}$ \\
\hline Dry matter & 78.12 & 78.80 & 78.93 & 79.91 & 3.2 & 0.4510 & 0.8060 & 0.7359 \\
\hline Nitrogen & 76.26 & 76.03 & 76.87 & 76.01 & 2.1 & 0.6721 & 0.4385 & 0.6514 \\
\hline Gross energy & 76.90 & 79.47 & 77.87 & 79.50 & 2.8 & 0.4573 & 0.4000 & 0.4922 \\
\hline
\end{tabular}

${ }^{1}$ Dietary Fiber.

${ }^{2}$ Benzoic acid: VevoVitall, DSM Nutrition Products, Basel, Switzerland.

${ }^{3}$ Standard error.

\section{Noxious gas emissions from slurry}

Fecal $\mathrm{NH}_{3}$ for DF and BA did not differ (for days 3, 5, and 7). Fecal RSH for DF showed significant reductions (for days 3, 5, and 7) as it did for BA (for days 3, 5, and 7). Fecal $\mathrm{H}_{2} \mathrm{~S}$ for DF showed significant reductions (for days 3, 5, and 7) as it did for BA (for days 3, 5, and 7). Thus, dietary fiber and BA supplementation did not affect $\mathrm{NH}_{3}$ emissions, but showed significant reductions in fecal $\mathrm{RSH}$ and $\mathrm{H}_{2} \mathrm{~S}$ emissions $(\mathrm{P}<0.05)$. Thus the concentrations of noxious gas emissions $\left(\mathrm{RSH}\right.$ and $\mathrm{H}_{2} \mathrm{~S}$ ) were influenced by the dietary treatments (Table 4).

\section{Blood lipid profile}

Serum cholesterol, total LDL, HDL, TG, and NEFA were not influenced by DF or BA treatments or any interaction (Table 5). For serum cholesterol, with the low energy diets for DF and BA at day 42, it was increased compared to day 0 , but the difference was not statistically significant $(\mathrm{P}>0.05)$. Also in serum total LDL, HDL, 
there were only slight changes in values between days 0 and 42 with DF and BA treatments. Thus, overall total blood lipid profiles with DF and BA treatments were found to be statistically insignificant $(\mathrm{P}>0.05)$ by ANOVA.

Table 4. Effect of dietary fiber (DF) and benzoic acid (BA) on harmful gas emissions (ppm) in the manure of growing pigs

\begin{tabular}{|c|c|c|c|c|c|c|c|c|}
\hline \multirow{2}{*}{$\begin{array}{c}\text { Dietary Fiber level (DF) }^{1} \\
\text { Benzoic Acid (BA) }^{2} \% \\
\end{array}$} & \multicolumn{2}{|c|}{ Low } & \multicolumn{2}{|c|}{ High } & \multirow{2}{*}{$\mathrm{SE}^{3}$} & \multicolumn{3}{|c|}{ P-value } \\
\hline & 0 & 5 & 0 & 5 & & DF & BA & $\mathrm{DF} \times \mathrm{BA}$ \\
\hline \multicolumn{9}{|l|}{ Ammonia $\left(\mathrm{NH}_{3}\right)$} \\
\hline 1 day & 4.40 & 4.28 & 5.60 & 4.15 & 1.256 & 0.4087 & 0.2336 & 0.3121 \\
\hline 3 day & 14.70 & 14.1 & 14.28 & 13.60 & 2.876 & 0.7533 & 0.6655 & 0.9796 \\
\hline 5 day & 18.85 & 18.30 & 18.08 & 18.00 & 2.729 & 0.7005 & 0.8227 & 0.8647 \\
\hline 7 day & 21.33 & 20.10 & 20.53 & 19.85 & 2.668 & 0.7009 & 0.4901 & 0.8402 \\
\hline \multicolumn{9}{|l|}{ Mercaptan (RSH) } \\
\hline 1 day & 0.50 & 0.25 & 0.25 & 0.25 & 0.01 & 0.6396 & 0.6396 & 0.6396 \\
\hline 3 day & 22.6 & 21.0 & 21.2 & 22.1 & 0.5 & 0.008 & 0.001 & 0.762 \\
\hline 5 day & 28.7 & 26.9 & 25.1 & 25.0 & 0.4 & $<0.001$ & 0.002 & 0.512 \\
\hline 7 day & 28.9 & 26.5 & 26.3 & 26.1 & 0.3 & $<0.001$ & 0.009 & 0.746 \\
\hline \multicolumn{9}{|l|}{ Hydrogen Sulfide $\left(\mathrm{H}_{2} \mathrm{~S}\right)$} \\
\hline 1 day & 0.25 & 0.25 & 0.25 & 0.25 & 0.01 & 1.0000 & 1.0000 & 1.0000 \\
\hline 3 day & 15.7 & 12.1 & 12.3 & 12.0 & 0.4 & $<0.001$ & 0.003 & 0.820 \\
\hline 5 day & 24.1 & 21.2 & 20.5 & 20.2 & 0.5 & 0.001 & 0.002 & 0.513 \\
\hline 7 day & 29.1 & 27.0 & 26.5 & 25.5 & 0.3 & $<0.001$ & 0.006 & 0.105 \\
\hline
\end{tabular}

${ }^{1}$ Dietary Fiber.

${ }^{2}$ Benzoic acid: VevoVitall, DSM Nutrition Products, Basel, Switzerland.

${ }^{3}$ Standard error.

Table 5. Effect of dietary fiber (DF) and benzoic acid (BA) on lipid profile of growing pigs

\begin{tabular}{|c|c|c|c|c|c|c|c|c|}
\hline \multirow{2}{*}{$\frac{\text { Dietary Fiber level (DF) }}{1}$} & \multicolumn{2}{|c|}{ Low } & \multicolumn{2}{|c|}{ High } & \multirow{2}{*}{$\mathrm{SE}^{3}$} & \multicolumn{3}{|c|}{ P-value } \\
\hline & 0 & 5 & 0 & 5 & & DF & BA & $\mathrm{DF} \times \mathrm{BA}$ \\
\hline \multicolumn{9}{|l|}{ Cholesterol (mg/dL) } \\
\hline Day 0 & 90.50 & 85.75 & 92.75 & 94.75 & 1.9 & 0.7707 & 0.2461 & 0.4784 \\
\hline Day 42 & 97.25 & 86.00 & 101.50 & 93.25 & 2.1 & 0.1241 & 0.3487 & 0.8035 \\
\hline \multicolumn{9}{|l|}{$\mathrm{LDL}^{4}(\mathrm{mg} / \mathrm{dL})$} \\
\hline Day 0 & 60.00 & 52.25 & 59.00 & 60.75 & 1.3 & 0.4440 & 0.3420 & 0.2340 \\
\hline Day 42 & 59.00 & 52.75 & 59.75 & 56.25 & 1.2 & 0.3406 & 0.6730 & 0.7843 \\
\hline \multicolumn{9}{|l|}{$\mathrm{HDL}^{5}(\mathrm{mg} / \mathrm{dL})$} \\
\hline Day 0 & 33.25 & 33.50 & 33.75 & 34.50 & 1.0 & 0.7727 & 0.6656 & 0.8850 \\
\hline Day 42 & 35.25 & 35.75 & 31.50 & 36.25 & 1.1 & 0.3044 & 0.5191 & 0.4021 \\
\hline \multicolumn{9}{|l|}{$\mathrm{TG}^{6}(\mathrm{mg} / \mathrm{dL})$} \\
\hline Day 0 & 47.75 & 50.50 & 48.50 & 50.75 & 1.3 & 0.7909 & 0.9577 & 0.9788 \\
\hline Day 42 & 49.25 & 55.50 & 65.25 & 53.50 & 1.5 & 0.5911 & 0.1854 & 0.0960 \\
\hline \multicolumn{9}{|l|}{$\mathrm{NEFA}^{7}(\mu \mathrm{Eq} / \mathrm{L})$} \\
\hline Day 0 & 140.75 & 143.50 & 141.25 & 142.50 & 3.2 & 0.8766 & 0.9845 & 0.9535 \\
\hline Day 42 & 113.50 & 93.25 & 114.50 & 110.75 & 3.1 & 0.2010 & 0.3175 & 0.3706 \\
\hline
\end{tabular}

${ }^{1}$ Dietary Fiber.

${ }^{2}$ Benzoic acid: VevoVitall, DSM Nutrition Products, Basel, Switzerland.

${ }^{3}$ Standard error.

${ }^{4} \mathrm{LDL}$ - Low density lipoprotein.

${ }^{5} \mathrm{HDL}-$ High density lipoprotein.

${ }^{6} \mathrm{TG}$ - Triglyceride.

${ }^{7} \mathrm{NEFA}$ - Non-esterified fatty acid. 


\section{Discussion}

\section{Growth performance and nutrient digestibility}

Livestock production can make good use of resources, which contributes high quality nutrients to the human diet (Mohana Devi et al., 2014 b). Feeding of DF-enriched diets to pigs is attracting interest from economic and social perspectives. However, ineffective results of fiber on growth performance of pigs and nutrient digestibility have been described and attributed to chemical and physical properties of the fiber (Graham et al., 1986). In the present work, there was no significant difference in body weight gain or feed efficiency between the LF and HF groups. Wenk (2001) showed that the retention time of digesta in the stomach was increased in the presence of DF and this early satiety could restrict voluntary feed intake in the pigs. The study of Zervas and Zijlstar (2002) found that pigs fed with a diet containing $15 \%$ soy hull or $20 \%$ sugar beet pulp show reduced $\mathrm{E}$ and $\mathrm{N}$ digestibility and growth performance. In the present work, DM, nitrogen and GE digestibility remained unchanged when the pigs consumed the high fiber diet. Others have reported that an increase of soluble DF in the diet impaired nutrient digestion and absorption, decreasing the total digestibility of nutrients (Rerat, 1985; Wilfart et al., 2007). A cannula study by Anguita et al. (2006) found that the ileal flow of digesta was increased, from 199 to $468 \mathrm{~g} / \mathrm{kg}$ of DM feed, as NSP increased from 77 to $240 \mathrm{~g} / \mathrm{kg}$, leading to a reduction in energy digestibility.

Benzoic acid and its salts have been used for many years as preservative agents due to their strong efficacy against various fungi and yeasts. Like other acidifiers, BA has been shown to have a beneficial effect on the growth performance of pigs (Mroz, 2005). Mohana Devi et al. (2014 a) reported that supplementation of protein sources in growing pig diets improved the growth rate and feed intake. However, BA did not have a direct or interactive effect on pig performance in the current study, and $5 \%$ addition of BA did not affect the DM, N and GE digestibility. On the contrary, in the experiments of Kluge et al. $(2006,2010)$ supplementation of diet with $2 \%$ BA significantly improved the digestibility of dietary organic matter, protein, fat and fiber compared to control diet. According to Kluge et al. (2006), BA is also able to modify bacterial populations of the gastrointestinal tract of the piglets and enhance their performance after weaning and this is due to its antibacterial activity. The dietary addition of BA resulted in increased average daily weight gain and significant improvements in feed conversion (Paulus et al., 2004). We expected that the addition of BA to the HF diet would compensate for the reduction in growth performance and digestibility of nutrients caused by the increase in fiber content. The lack of an interaction may have reflected the use of the relatively low level of fiber, the high level of nutrients in the diet, and the clean environmental status of the trial farm. According to Papatsiros et al. (2011), administration of BA improved the growth performance parameters and reduced the severity of diarrhea in weaning pigs. Addition of $1 \% \mathrm{BA}$ to a standard diet for growing pigs acidifies the urinary $\mathrm{pH}$ and slightly reduces blood $\mathrm{pH}$ (Kristensen et al., 2009). Additionally, BA in the diet of lactating sows is effective in reducing the $\mathrm{pH}$ values in the urine and higher concentrations of $\mathrm{BA}(2 \%)$ in the diet improve nutrient digestibility (Kluge et al., 2010). 


\section{Gas emissions}

In many developed countries, environmental pollution is a growing issue and harmful gases, such as ammonia, can diminish the growth performance of pigs (Van der Peet-Schwering, 1999). Ammonia emissions from pig barns are formed mainly due to the enzymatic conversion of the urea in urine (Muck and Steenhuis, 1981). The ammonia production process is influenced by factors that include the urinary urea concentration, the $\mathrm{pH}$ and temperature of the slurry, air flow, and surface area (Sommer and Husted, 1995). Studies have sought to achieve reductions in ammonia in the pig industry through dietary manipulation (Panetta et al., 2006; Botermans et al., 2010). One approach is to give a diet enriched with fermentable fiber to pigs. Dietary fiber can aid in lowering $\mathrm{pH}$ in the slurry as a consequence of short chain fatty acid (SCFA) production, thus reducing urease activity. Dietary fiber may reduce the decomposable $\mathrm{N}$ content in the urine by $\mathrm{N}$ repartitioning effects. Canh et al. (1998) found that the slurry $\mathrm{pH}$ of male finisher pigs fed with a sugar beet pulp-based diet (at $300 \mathrm{~g} / \mathrm{kg}$ ) was 0.8 units lower and ammonia emissions were 52\% lower than those from pigs fed with barley-wheat-, tapioca-, and barley-tapioca-based diets. Mroz et al. (2000) also confirmed the $\mathrm{N}$ repartitioning effect of fiber in manure of pigs fed with diets containing tapioca, soybean hulls, and sugar beet pulp.

Another approach to reducing ammonia emission is the addition of BA in the diet. BA is metabolized in the liver and is converted to hippuric acid by conjugation with the amino acid glycine. Increased excretion of hippuric acid in pig urine results in its direct acidification (den Brok et al., 1999). Aarnink et al. (2008) reported that the dietary addition of $1 \%$ BA reduced ammonia emissions by $16 \%$ and decreased the $\mathrm{pH}$ in pig manure from 6.50 to 5.29 . Because $0.5 \% \mathrm{BA}$ is used commercially, we used the same level of BA in the diet and $\mathrm{NH}_{3}$ gas emission from slurry was apparently unaffected by the level of fiber and the addition of BA. It might be assumed that the amounts of DF and BA were not sufficient to reduce $\mathrm{NH}_{3}$ gas emissions, but levels of $\mathrm{RSH}$ and $\mathrm{H}_{2} \mathrm{~S}$ were reduced significantly by the treatments.

\section{Blood metabolites or lipid profile}

The introduction of agriculture and animal husbandry and developments in agricultural technology have driven a marked increase in the consumption of animal protein and processed carbohydrates by humans. These dietary changes affect the physiological environment in the body. One of the physiological changes influenced by food consumption is blood cholesterol levels (Cordain, 2007).

Blood cholesterol is an important factor in the diagnosis of health status in humans because it is a major risk factor for cardiovascular diseases (Grundy, 1986). Many studies have focused on reducing the risk of coronary heart disease (CHD) through dietary interventions (Gaylor et al., 1960; Monique-Verschuren and Kromhout, 1995; Shen et al., 1998). Kendall et al. (2010) demonstrated that an overall $1 \%$ reduction in serum levels of LDL-cholesterol corresponded to $\sim 1-2 \%$ reduction in the occurrence of CHD events. Brown et al. (1999) reported that various soluble fibers can reduce total and LDL-cholesterol by similar amounts. Dietary fiber binds to bile acids in the small intestine and makes them less likely to enter the body and decreases intestinal lipid absorption and subsequently reduces the level of blood 
cholesterol (Brown et al., 1999; Wilfart et al., 2007; Anderson et al., 2009). Furthermore, microbes in the large intestine can ferment the undigested fiber. When DF is fermented, SCFAs such as propionic acid, butyric acid, and acetic acid are produced. SCFAs suppress cholesterol synthesis by the liver and reduce blood levels of LDL cholesterol and TG (Wong et al., 2006). In animal studies, Graham et al. (1986) observed that DF, such as wheat bran and sugar beet pulp, decreased small intestinal lipid absorption. Weber and Kerr (2012) reported that DF increased the capacity of the intestine for oxidative metabolism and induced a repartitioning of body lipid stores via mobilization of non-esterified fatty acids (NEFA). Collings et al. (1979) found that serum cholesterol levels were decreased in male pigs when more than $10 \%$ of wheat middlings were included in corn-soybean-based diets for growing pigs. In a study using guinea pigs, plasma cholesterol was found to be lowered in females fed with soluble DF, such as pectin, guar gum, and psyllium (Shen et al., 1998).

Benzoic acid has structural and metabolic similarities to niacin (Schanker et al., 1958). Niacin rapidly decreases TG levels by inhibiting the release of fatty acids from adipose tissue, as well as the hepatic synthesis of fatty acids (Kamanna and Kashyap, 2000). Reduced TG synthesis may enhance hepatic degradation of apo B, the major lipoprotein component of very low-density lipoprotein (VLDL), thereby reducing VLDL production and LDL content in the body (Jin et al., 1999). The reduction in TG availability also results in the production of smaller, TG-poor VLDL particles, which inhibits the production of small, dense LDL particles. Niacin may elevate HDL cholesterol levels too, primarily by suppressing the hepatic removal of apo A-I, which increases levels of apo A-I as well as large apo A-I-containing HDL particles (Jin et al., 1997). Niacin is excreted in the form of nicotine uric acid conjugated with glycine and BA is also excreted in the urine by conjugation with glycine (Schachter, 1957). Because the structure and excretory mechanism are similar between niacin and BA, BA may have an effect of decreasing LDL in the blood.

The present study found no effect of DF and BA on the blood characteristics assessed. The lack of effect of fiber on the blood cholesterol of pigs disagrees with the findings of Shen et al. (1998). The disagreement may have resulted from the different inclusion rates and sources of fiber. We now consider that $50 \mathrm{~g}$ of sugar beet pulp per kg of diet may have been insufficient to reduce serum cholesterol in grower pigs. The findings of this study also suggest the metabolism of benzoic acid may differ from that of niacin.

\section{Conclusions}

It can be concluded that the addition of $50 \mathrm{~g} / \mathrm{kg}$ sugar beet pulp as a source of DF in grower pig feed did not obviously affect growth performance or serum metabolites in pigs, but the harmful gas emissions $\left(\mathrm{RSH}\right.$ and $\mathrm{H}_{2} \mathrm{~S}$ ) were influenced by this supplementation of DF and the addition of $5 \mathrm{~g} / \mathrm{kg} \mathrm{BA}$ in the diet. Thus, a moderate level of DF in the diet would not unfavorably affect the growth performance of growing pigs, and has some significant influence in reducing $\mathrm{RSH}$ and $\mathrm{H}_{2} \mathrm{~S}$ gas emissions. 


\section{References}

A a r n in k A.J.A., H o 1 M.G., N i j e b o e r G.M. (2008). Ammonia emission factor for using benzoic acid ( $1 \%$ vevovitall) in the diet of growing-finishing pigs. Animal Sciences Group of Wageningen UR, Report 133, Divisie Veehouderij, Lelystad.

Anders on J.W., B a ird P., D a vis R.H.Jr., F erreri S., Knudts on M., K or a y m A., Wate r s V., Willi a m s C.L. (2009). Health benefits of dietary fiber. Nutr. Rev., 67: 188-205.

Anguita M., Canibe N., P erez J.F., J en sen B.B. (2006). Influence of the amount of dietary fiber on the available energy from hindgut fermentation in growing pigs: Use of cannulated pigs and in vitro fermentation. J. Anim. Sci., 84: 2766-2778.

B ot e r man s J., Gustafs s o n G., J e p p s s on K.H., B row in N., R odhe L. (2010). Measures to reduce ammonia emissions in pig production - Review. Report 12, Landscape Horticulture Agriculture Reportseries, Uppsala.

B row n L., R o s ner B., Willet t W.W., S a c k s F.M. (1999). Cholesterol-lowering effects of dietary fiber: a meta-analysis. Am. J. Clin. Nutr., 69: 30-42.

B uhle r K., We n k C., B roz J., G e bert S. (2006). Influence of benzoic acid and dietary protein level on performance, nitrogen metabolism and urinary $\mathrm{pH}$ in growing-finishing pigs. Arch. Anim. Nutr., 60: 382-389.

Canh T.T., Sutton A.L., A arnink A.J.A., Verstegen M.W.A., S chrama J.W., Bakk e r G.C. (1998). Dietary carbohydrates alter the fecal composition and $\mathrm{pH}$ and the ammonia emission of slurry from growing-finishing pigs. J. Anim. Sci., 76: 1887-1895.

Chandalia M., Garg A., Lutjohann D., von Bergmann K., Grundy S.M., Brinkle y L.J. (2000). Beneficial effects of high dietary fiber intake in patients with type 2 diabetes mellitus. New Eng. J. Med., 342: 1392-1398.

Ch e o n g J.Y. (2013). Effects of fiber on performance of weaned and growing-finishing pigs. PhD. dissertation, Dankook University, Cheonan, Korea.

C h o J.H., K i m I.H. (2014). Effects of lactulose supplementation on performance, blood profiles, excreta microbial shedding of Lactobacillus and Escherichia coli, relative organ weight, and excreta noxious gas contents in broilers. J. Anim. Physiol. Anim. Nutr., 98: 424-430.

Cho J.H., Z hang Z.F., K im I.H. (2013). Effects of fermented grains as raw cereal substitutes on growth performance, nutrient digestibility, blood profiles, and fecal noxious gas emission in growing pigs. Livest. Sci., 154: 131-136.

Colling s G.F., Ericks on J.P., Yok o y a m a M.T., Miller E.R. (1979). Effect of wheat middlings on fiber digestibility, serum cholesterol and glucose and fecal bile acids in pigs. J. Anim. Sci., 49: $528-534$.

C o r d a in L. (2007). Implications of Plio-Pleistocene hominin diets for modern humans. In: Evolution of the human diet: The known, the unknown, and the unknowable, Ungar P. (ed.). Oxford University Press, New York, pp. 363-383.

D e n B rok G.M.,H endriks J.G.L., Vri e link M.G.M., va n d e r P e e t-S chw e ringC.M.C. (1999). Urinary $\mathrm{pH}$, ammonia emission and performance of growing/finishing pigs after the addition of a mixture of organic acid, mainly benzoic acid, to the feed. Research Institute for Pig Husbandry, Netherlands.

G a y lor J.L., H a r d y R.W.F., B a u m a n n C.A. (1960). Effects of nicotinic acid and related compounds on sterol metabolism in the chick and rat. J. Nutr., 70: 293-301.

Grah a m H., H e s s e $1 \mathrm{~m}$ a n K., A m a n P. (1986). The influence of wheat bran and sugar-beet pulp on the digestibility of dietary components in a cereal-based pig diets. J. Nutr., 116: 242-251.

Grun d y S.M. (1986). Cholesterol and coronary heart disease - A new era. J. Am. Med. Assoc., 256: 2849-2858.

H o n g S.M., H u a n g J.H., K i m I.H. (2012). Effect of medium-chain triglyceride (MCT) on growth performance, nutrient digestibility, blood characteristics in weanling pigs. Asian-Australasian J. Anim. Sci., 25: 1003-1008.

J in F.Y., K a mann a V.S., K a s h y a p M.L. (1997). Niacin decreases removal of high-density lipoprotein apolipoprotein A-I but not cholesterol ester by Hep G2 cells: implication for reverse cholesterol transport. Arterioscler. Thromb. Vasc. Biol., 17: 2020-2028.

J in F.Y., K a m a n a V.S., K a s h y a M.L. (1999). Niacin accelerates intracellular Apo B degrada- 
tion by inhibiting triacylglycerol synthesis in human hepatoblastoma (HepG2) cells. Arterioscler. Thromb. Vasc. Biol., 19: 1051-1059.

K a m a n n a V.S., K a s h y a p.L. (2000). Mechanism of action of niacin on lipoprotein metabolism. Curr. Atheroscler. Rep., 2: 36-46.

Kenda 11 C.W.C., Es fah a n i A., Jenk in s D.J.A. (2010). The link between dietary fibre and human health. Food Hydrocolloid, 24: 42-48.

Kluge H., Broz J., Eder K. (2006). Effect of benzoic acid on growth performance, nutrient digestibility, nitrogen balance, gastrointestinal microflora and parameters of microbial metabolism in piglets. J. Anim. Physiol. Anim. Nutr (Berl.), 90: 316-324.

Kluge H., Broz J., Eder K. (2010). Effects of dietary benzoic acid on urinary pH and nutrient digestibility in lactating sows. Livest. Sci., 134: 119-121.

Kri s t e n s e n N.B.,N o r g a a r d J.,W a m b e r g S.,E n g b a e k M.,F e r n a n d e z J.A.,Z a c ho H.D., P o u l s e n H.D. (2009). Absorption and metabolism of benzoic acid in growing pigs. J. Anim. Sci., 87: 2815-22.

Mateos G.G., Martin F., Lat orre M.A., Vic ente B., L a zaro R. (2006). Inclusion of oat hulls in diets for young pigs based on cooked maize or cooked rice. Anim. Sci., 82: 57-63.

McMillan-Price J., Petocz P., Atkinson F., O'Enill K., Samman S., Steinbe c k K., C a ters on I., B r a n d - Mille r J. (2006). Comparison of 4 diets of varying glycemic load on weight loss and cardiovascular risk reduction in overweight and obese young adults. Arch. Int. Med., 166: 1466-1475.

M e uni er-S a l u n M.C., E dward s S.A., R o bert S. (2001). Effect of dietary fiber on the beavior and health of the restricted fed sow. Anim. Feed Sci. Tech., 90: 53-69.

Mohana Devi S., Devi U.S., Kim I.H. (2014 a). Evaluation of dietary sources of protein on growth performance in pigs. Vet. Med., 59: 247-253.

Mohan a Devi S., B a l a chand a r V., L e e S.I., K i m I.H. (2014 b). An outline of meat consumption in the Indian population - A pilot review. Korean J. Food Sci. Ann. Res., 34: 507-515.

Monique-Ver s churen W.M., Krom hout D. (1995). Total cholesterol concentration and mortality at a relatively young age: do men and women differ? Brit. Med. J., 311: 779-783.

Mosenthin R., S a u er W.C., Henkel H., A hrens F., de L ange C.F. (1992). Tracer studies of urea kinetics in growing pigs: II. The effect of starch infusion at the distal ileum on urea recycling and bacterial nitrogen excretion. J. Anim. Sci., 70: 3467-3472.

Mroz Z. (2005). Organic acids as potential alternatives to antibiotic growth promoters for pigs. Adv. Pork Prod., 16: 169-182.

Mroz Z., Moeser A.J., Vreman K., van Diepen J.T.M., van Kempen T., Canh T.T., J on g bloed A.W. (2000). Effects of dietary carbohydrates and buffering capacity on nutrient digestibility and manure characteristics in finishing pigs. J. Anim. Sci., 78: 3096-3106.

M u c k R.E., S t e e n hu is T.S. (1981). Nitrogen losses in free stall dairy barns. In Livestock Waste: A Renewable Resource, St. Joseph, MI, ASAE, pp. 406-409.

$\mathrm{N}$ a h m K.H. (2003). Influences of fermentable carbohydrates on shifting nitrogen excretion and reducing ammonia emission of pigs. Crit. Rev. Env. Sci. Tech., 33: 165-186.

P a n e t t a D.M., P ow e r s W.J., X in H., K e r r B.J., S t a l d e r K.J. (2006). Nitrogen excretion and ammonia emissions from pigs fed modified diets. J. Env. Qual., 35: 1297-308.

Papatsiros VG., Tass is P.D., Tzika E.D., Papaioannou D.S., Petridou E., Alexopoulos C., Kyriakis S.C. (2011). Effect of benzoic acid and combination of benzoic acid with probiotic containing Bacillus cereus var Toyoi in weaned pig nutrition. Polish J. Vet. Sci., 14: $117-125$.

P a u l u s C., L e v r o u w L., G e e r s R. (2004). How to combine performance and environmental care? Proc. VevoVitall. International Society for Animal Hygiene (ISAH) Congress "Animal production in Europe: The way forward in a changing world", Saint-Malo, France, 11-13.10.2004, p. 85.

P ierce K.M., Callan J.J., McCarthy P., O' Doherty J.V. (2007). The interaction between lactose level and crude protein concentration on piglet post-weaning performance, nitrogen metabolism, selected faecal microbial populations and faecal volatile fatty acid concentrations. Anim. Feed Sci. Tech., 132: 267-282.

R e r a t A. (1985). Intestinal absorption of end products from digestion of carbohydrates and proteins in the pig. Arch. Anim. Nutr., 35: 461-480. 
Sauer W., Cervantes M., Yanez J., Araiza B., Murdoch G., Morales A., Zij1stra R.T. (2009). Effect of dietary inclusion of benzoic acid on mineral balance in growing pigs. Livest. Sci., 122: 162-168.

$\mathrm{S}$ ch a chter D. (1957). The chemical estimation of acylglucuronides and its application to studies on the metabolism of benzoate and salicylate in man. J. Clin. Invest., 36: 297-302.

S chanker L.S., To c c o D.J., B rod i e B.B., Ho g b e n C.A.M. (1958). Absorption of drugs from the rat small intestine. J. Pharm. Exp. Therap., 123: 81-88.

S chulze M.B., Liu S., Rim m E.B., Man s on J.E., Wille t t W.C., H u F.B. (2004). Glycemic index, glycemic load, and dietary fiber intake and incidence of type 2 diabetes in younger and middle-aged women. Am. J. Clin. Nutr., 80: 348-356.

S erena A., J orgen sen H., B a c h Knudsen K.E. (2009). Absorption of carbohydrate-derived nutrients in sows as influenced by types and contents of dietary fiber. J. Anim. Sci., 87: 136-147.

Sh e n H., H e L., P r i c e R.L., F e r n a n d e z M.L., (1998). Dietary soluble fiber lowers plasma LDL cholesterol concentrations by altering lipoprotein metabolism in female guinea pigs. J. Nutr, 128: 1434-1441.

S o m m e r S.G., H u s te d S. (1995). A simple model of pH in slurry. J. Agri. Sci., 124: 447-453.

Van der Peet-Schwering C.M.C., A arnink A.J.A., Rom H.B., D ourmad J.Y. (1999). Ammonia emission from pig houses in The Netherlands, Denmark and France. Livest. Prod. Sci., 58: 265-269.

W a n g J.P., Y o o J.S., L e e J.H., J a n g H.D., K i m H.J., S h i n S.O., S e o n g S.I., K i m I.H. (2009). Effects of phenyllactic acid on growth performance, nutrient digestibility, microbial shedding, and blood profile in pigs. J. Anim. Sci., 87: 3235-3243.

W e b e r T.E., K e r r B.J. (2012). Metabolic effects of dietary sugar beet pulp or wheat bran in growing female pigs. J. Anim. Sci., 90: 523-532.

We 11 ock I.J., Fortomaris P.D., Houdijk J.G.M., Wis em an J., Kyriazakis I. (2008). The consequences of non-starch polysaccharide solubility and inclusion level on the health and performance of weaned pigs challenged with enterotoxigenic Escherichia coli. Br. J. Nutr., 99: $520-530$.

We $\mathrm{n}$ k C. (2001). The role of dietary fiber in the digestive physiology of the pig. Anim. Feed Sci. Tech., 90: 21-33.

Wilfart A., Montagne L., Simmins P.H., van Milgen J., Noblet J. (2007). Sites of nutrient digestion in growing pigs: Effect of dietary fiber. J. Anim. Sci., 85: 976-983.

W i 11 i a m s C.H., D a vid D.J., I is m a O. (1962). The determination of chromic oxide in faeces samples by atomic absorption spectrophotometry. J. Agri. Sci., 59: 381-385.

Wong J.M., de Souza R., Kendall C.W., Emam A., Jenkins D.J. (2006). Colonic health: Fermentation and short chain fatty acids. J. Clin. Gastroenterol., 40: 235-243.

Y a n L., K i m I.H. (2012). Effect of eugenol and cinnamaldehyde on the growth performance, nutrient digestibility, blood characteristics, fecal microbial shedding and noxious gas content in growing pigs. Asian-Australasian J. Anim. Sci., 25: 1178-1183.

Z e rvas S., Zij $1 \mathrm{str}$ a R.T. (2002). Effects of dietary protein and oat hull fiber on nitrogen excretion patterns and postprandial plasma urea profiles in grower pigs. J. Anim. Sci., 80: 3238-3246.

Z ha n g Z.F., K i m I.H. (2013). Effects of probiotic supplementation in different energy and nutrient density diets on performance, egg quality, excreta microflora, excreta noxious gas emission, and serum cholesterol levels in laying hens. J. Anim. Sci., 91: 4781-4787.

Received: 18 VI 2014

Accepted: 18 XI 2014 